\title{
EFFECT OF THERMOMECHANICAL STRATEGY AND MO-NB-B ALLOYING ADDITIONS ON HIGH STRENGTH MEDIUM CARBON Q/Q\&T STEELS
}

\author{
I. Zurutuza ${ }^{1,2}$, N. Isasti ${ }^{1,2}$, E. Detemple ${ }^{3}$, V. Schwinn ${ }^{3}$, H. Mohrbacher ${ }^{4}$ and P. Uranga ${ }^{1,2}$ \\ ${ }^{1}$ Ceit, Donostia / San Sebastián, Basque Country, Spain \\ ${ }^{2}$ Universidad de Navarra, Tecnun, Donostia / San Sebastián, Basque Country, Spain \\ ${ }^{3} \mathrm{AG}$ der Dillinger Hüttenwerke, Dillingen, Germany \\ ${ }^{4}$ NiobelCon bvba, Schilde, Belgium
}

Keywords: martensite, CCT diagrams, Direct Quenching, niobium, molybdenum

\begin{abstract}
The substitution of conventionally quenched and tempered (Q\&T) plates by thermomechanically treated ultra-high strength steels is becoming widely accepted in industry. Austenite conditioning during rolling followed by Direct Quenching (DQ) might offer benefits in mechanical properties. The metallurgical mechanisms behind these different routes, though, are not clear; especially when different combinations of microalloying elements such as $\mathrm{B}$, Mo and/or $\mathrm{Nb}$ are combined. Deformation dilatometry studies were performed with several microalloyed medium carbon grades. Their transformation behavior was analyzed when different thermomechanical strategies were applied and differences on the hardenability of each alternative were evaluated. Multipass torsion tests were also performed and the austenite conditioning before transformation studied. The relationship between austenite and final martensite microstructure was evaluated using the EBSD technique. This study aims to correlate the effect of composition and processing parameters in the final quenched structure.
\end{abstract}

\section{Introduction}

In response to the demanding strength and impact resistance market requirements, plates and pipes are usually quenched and tempered for several applications. The use of boron as an alloying element is a widely known practice in high strength medium carbon Q/Q\&T steels to increase the strength due its ability for delaying phase transformation, enhancing hardenability and ensuring the formation of bainitic/martensitic microstructures. These steels are being considered as the material of choice for many advanced applications where yield strength above $500 \mathrm{MPa}$ is required to reduce component weight [1]. Mo addition is justified when ultrahigh strength steels are requested. The formation of low-temperature transformation products such as bainite and martensite could be achieved through the addition of Mo [2]. In addition, the combined addition of $\mathrm{Nb}$ and $\mathrm{B}$ to a Ti-protected low-carbon steel increases the tensile strength, which is mainly attributed to the suppression of $\mathrm{Fe}_{23}(\mathrm{C}, \mathrm{B})_{6}$ as a result of $\mathrm{NbC}$ precipitation [3]. Q/Q\&T steels are usually produced by a Direct Quenching process or by quenching after reheating of the rolled plate (named as Conventional Quenching). Recently, alternative hot rolling schedules are being developed followed by direct quenching, in order to avoid the re-austenitization stage. When multiple microalloy additions are needed, the definition of the optimum chemical composition and the thermomechanical route becomes complex due to the multiple effects interacting at the same time. In the current work, the synergetic behavior of $\mathrm{Nb}$, Mo and B enhancing solute drag effects 
and precipitation kinetics in austenite under hot working conditions is analyzed. In addition, the effect of addition of microalloying elements and heat treatment strategy on phase transformation is also evaluated. Finally, the analysis is also focused on the effect of austenite conditioning on the final quenched microstructure.

\section{Experimental}

The chemical composition of the studied steels is shown in Table I. In addition to a CMnB steel, three microalloyed steels have been selected, with $\mathrm{Nb}$, Mo and $\mathrm{Nb}-\mathrm{Mo}$ additions. All steels are Tialloyed to guarantee the B effect. Multipass torsion tests were carried out for the austenite conditioning determination. After a soaking at $120{ }^{\circ} \mathrm{C}$ for $10 \mathrm{~min}$, for $\mathrm{CMnB}$ and $\mathrm{CMnNbB}$ steels, 24 deformation passes were applied at decreasing temperature in the $1100{ }^{\circ} \mathrm{C}$ and $640{ }^{\circ} \mathrm{C}$ range. For the steels containing Mo, deformation passes were applied from $1200^{\circ} \mathrm{C}$. The temperature decrease between passes was of $20^{\circ} \mathrm{C}$. Different strain per passes of 0.2 and 0.3 and interpass times of $5 \mathrm{~s}$ and $15 \mathrm{~s}$ were selected. A strain rate of $1 \mathrm{~s}^{-1}$ was defined. The non-recrystallization temperature was defined considering the standard method proposed by Bai et al. [4].

Table I Chemical composition of the steels studied (weight percent).

\begin{tabular}{cccccccc}
\hline & $\mathrm{C}$ & $\mathrm{Si}$ & $\mathrm{Mn}$ & $\mathrm{Al}$ & $\mathrm{Nb}$ & $\mathrm{Mo}$ & $\mathrm{B}$ \\
\hline $\mathrm{CMnB}$ & 0.15 & 0.32 & 1.05 & 0.033 & - & - & 0.0022 \\
$\mathrm{CMnNbB}$ & 0.16 & 0.29 & 1.05 & 0.033 & 0.026 & - & 0.0019 \\
$\mathrm{CMnMoB}$ & 0.16 & 0.28 & 1.07 & 0.024 & - & 0.5 & 0.0022 \\
$\mathrm{CMnNbMoB}$ & 0.16 & 0.31 & 1.07 & 0.027 & 0.026 & 0.5 & 0.0018 \\
\hline
\end{tabular}

Dilatometry tests were performed in a Bähr DIL805D deformation dilatometer, using solid cylinders with a diameter of $5 \mathrm{~mm}$ and a length of $10 \mathrm{~mm}$. As shown in Figure 1, different thermomechanical schedules were defined in order to simulate different rolling and cooling strategies (Conventional Quenching (CQ), Direct Quenching (DQ) and DQ+CQ)). All cycles include a solution heat treatment at $1200^{\circ} \mathrm{C}$ for 10 minutes, with the aim of dissolving microalloying elements. Afterwards, the samples were deformed at 1175 and $1050^{\circ} \mathrm{C}$ (strain of 0.3 and strain rate of $1 \mathrm{~s}^{-1}$ ) in order to obtain fine recrystallized austenite. Concerning Conventional Quenching cycle (see Figure 1a), the specimens were cooled down slowly $\left(1^{\circ} \mathrm{C} / \mathrm{s}\right)$ to room temperature. After that, a second austenitization treatment was applied at $910^{\circ} \mathrm{C}$ for 15 minutes. Finally, a controlled cooling from $910^{\circ} \mathrm{C}$ was applied at cooling rates from $0.1^{\circ} \mathrm{C} / \mathrm{s}$ to maximum cooling. For Direct Quenching cycle (see Figure 1b), a third deformation pass of 0.3 was applied at $870^{\circ} \mathrm{C}$ below $\mathrm{T}_{\mathrm{nr}}$, with the purpose of accumulating deformation in the austenite prior to transformation, followed by a continuous cooling modifying the cooling rate. In the DQ+CQ schedule, the multipass sequence is similar to the one for DQ. After applying the last deformation pass, the samples were quenched from $870^{\circ} \mathrm{C}$ and a second austenitization was applied at $910^{\circ} \mathrm{C}$. In order to evaluate the effect of austenite conditioning on the final martensitic microstructure, hot rolling simulations were performed by multipass torsion tests. This study was focused on the evaluation of the total reduction applied during finishing passes below the non-recrystallization temperature. Therefore, different finishing deformation strategies (Low Deformation, Medium Deformation and High Deformation) were defined. After a soaking at $1200^{\circ} \mathrm{C}$ for $10 \mathrm{~min}$, in all cases 5 roughing deformation passes were applied in the $1170-1150{ }^{\circ} \mathrm{C}$ range. In these passes, a deformation of 0.2 , strain rate of $2 \mathrm{~s}^{-1}$ and an interpass time of $6 \mathrm{~s}$ were defined. Between roughing 
and finishing, transfer times of about 400s were applied. In finishing the reduction strategy was changed. In all cases, the Finish Rolling Temperature (FRT) was set at $830^{\circ} \mathrm{C}$ and the finishing passes were applied in the $880-830^{\circ} \mathrm{C}$. For the Low Deformation condition, two deformation passes of 0.2 were applied, for the Medium Deformation condition, 4 deformation passes and finally, for the High Deformation condition, 8 deformation passes were applied. After the deformation sequence, the same final cooling strategy was used based on a slow cooling down to $790^{\circ} \mathrm{C}$ and an accelerated cooling to room temperature (cooling rate of $30^{\circ} \mathrm{C} / \mathrm{s}$ ).

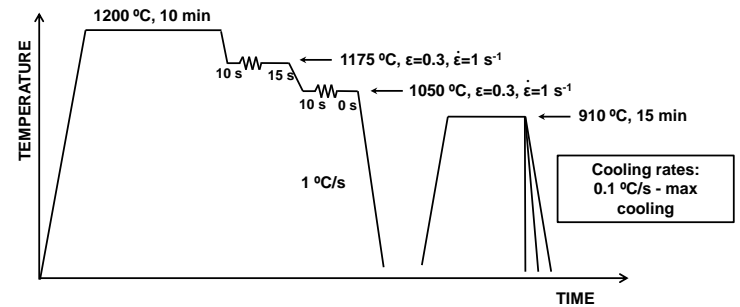

(a) Conventional Quenching (CQ)

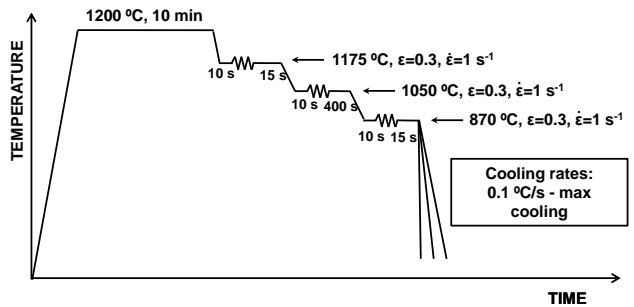

(b) Direct Quenching (DQ)

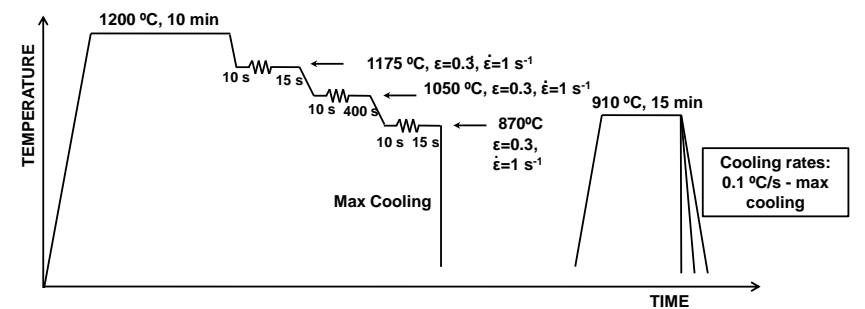

(c) Direct Quenching (DQ) + Conventional Quenching (CQ)

Figure 1. Thermomechanical schedules applied in the deformation dilatometer for determination of CCT diagram: (a) CQ, (b) DQ and (c) DQ+CQ.

\section{Results and discussion}

\section{$\underline{\text { Austenite Conditioning: Non-recrystallization temperature }}$}

In Figure 2a, an example of the mean flow stress curves obtained for the different steel grades is shown, corresponding to a deformation of 0.2 and an interpass time of $5 \mathrm{~s}$. The chemical composition affects notoriously in the non-recrystallization temperature. The addition of microalloying elements ( $\mathrm{Nb}$, Mo or Nb-Mo) increases considerably the Tnr temperature. Nonrecrystallization temperatures of $955,980,1010$ and $1024^{\circ} \mathrm{C}$ are estimated, for $\mathrm{CMnB}, \mathrm{CMnNbB}$, $\mathrm{CMnMoB}$ and $\mathrm{CMnNbMoB}$ steels, respectively. Besides the effect of microalloying addition, the influence of deformation parameters, such as deformation per pass and interpass time has to be considered. In Figure $2 b$ the influence of the interpass time can be evaluated for $\varepsilon=0.3$ and all chemistries. Figure $2 \mathrm{~b}$ shows that the reduction of interpass time leads to slightly higher Tnr values. As mentioned previously, when microalloying elements are added, higher Tnr temperatures are achieved. The lowest non-recrystallization temperatures are measured for CMnB steel, followed by $\mathrm{CMnNbB}, \mathrm{CMnMoB}$ and $\mathrm{CMnNbMoB}$. The interaction between precipitation and recrystallization in each chemistry and deformation condition, was estimated by the evaluation of the fractional softening occurring between deformation passes. In Figure $3 a$ and $b$, fractional softening for all the grades are plotted as a function of temperature, corresponding to the strain per pass of 0.3 and interpass times of $5 \mathrm{~s}$ and $15 \mathrm{~s}$, respectively. The softening behavior differs depending on the chemical composition and the applied interpass time. As expected, the decrease 
of softening starts at higher temperatures in microalloyed steels. This holds for both deformation levels. At high temperatures, in all the chemistries the softening drop could be related to the solute drag effect. In addition to the solute drag contribution, for the CMnNbB and CMnNbMoB steels, strain induced precipitation is the controlling mechanism retarding recrystallization. Concerning $\mathrm{CMnMoB}$ steel, complete recrystallization is not reached at the first deformation passes at high temperatures. The short interpass times and Mo solute drag effect avoids the complete softening during the first interpass temperature range.

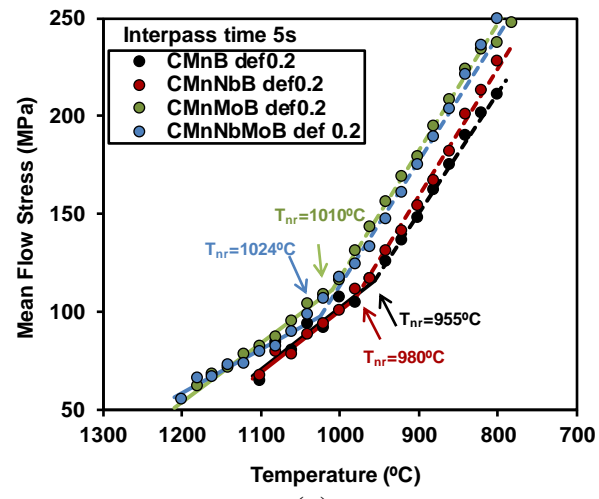

(a)

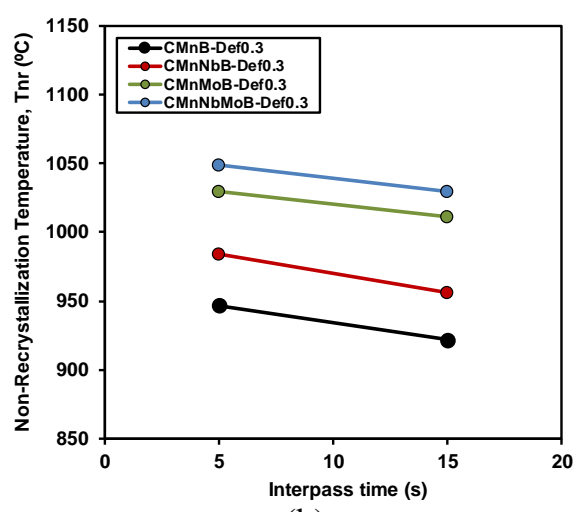

(b)

Figure 2 (a) Mean Flow Stress as a function of temperature (strain of 0.2 and interpass time of $5 \mathrm{~s}$ ). (b) Effect of interpass time and addition of microalloying elements on Tnr.

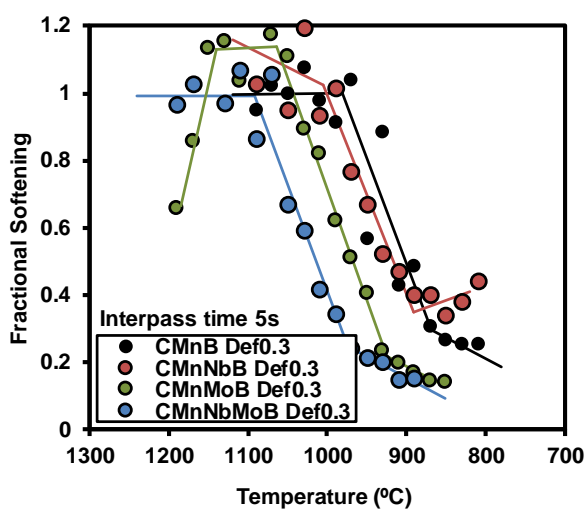

(a)

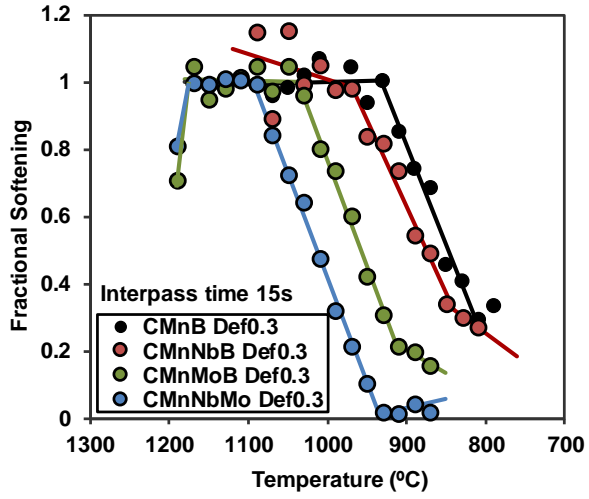

(b)

Figure 3 Fractional Softening as a function of temperature for all the steel grades and deformation of 0.3: (a) Interpass time of $5 \mathrm{~s}$ and (b) Interpass time of 15s.

\section{$\underline{\text { Phase transformations }}$}

Continuous Cooling Transformation (CCT) diagrams were built for all the steels and different thermomechanical schedules. As an example, in Figure 4a, the CCT diagram corresponding to the microalloyed steel with $\mathrm{Nb}$ and Mo after Direct Quenching sequence is shown. In addition to phase stability regions, cooling rates and Vickers hardness measurements are included in the CCT diagram. At the lowest cooling rate of $0.1^{\circ} \mathrm{C} / \mathrm{s}$, the microstructure is composed of ferrite and bainite, as shown in Figure 4b. The formation of ferrite is suppressed for cooling rates higher than $0.1^{\circ} \mathrm{C} / \mathrm{s}$. At intermediate cooling rates (see Figure 4c), mainly bainitic microstructures are noticed and the presence of martensite is observed for cooling rates higher than $5^{\circ} \mathrm{C} / \mathrm{s}$. Fully martensitic microstructures can be achieved after cooling rates higher than $50^{\circ} \mathrm{C} / \mathrm{s}$ (see Figure $4 \mathrm{~d}$ ). 


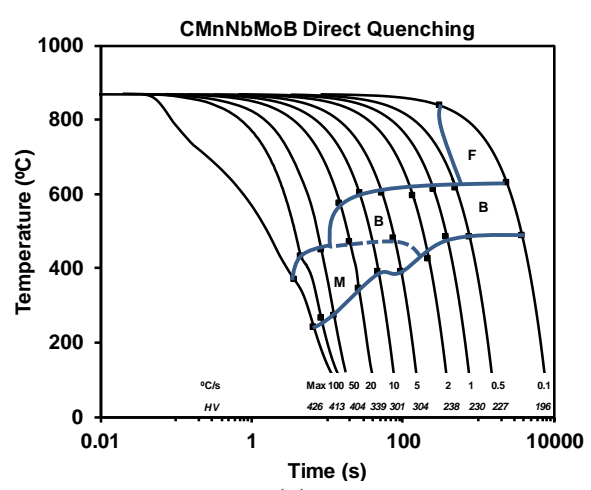

(a)

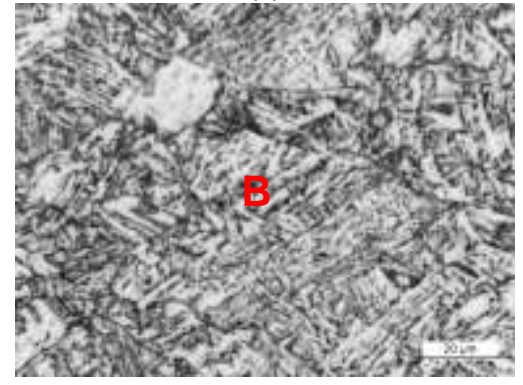

(c) $10^{\circ} \mathrm{C} / \mathrm{s}$

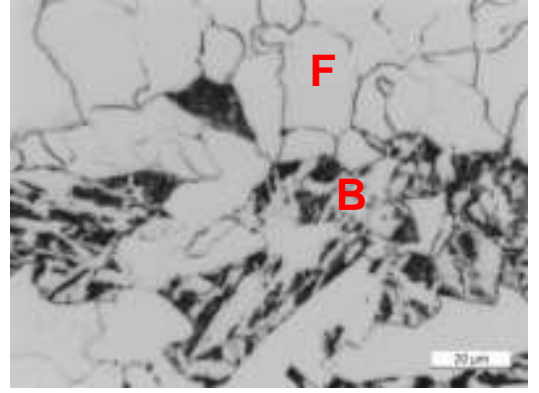

(b) $0.1^{\circ} \mathrm{C} / \mathrm{s}$

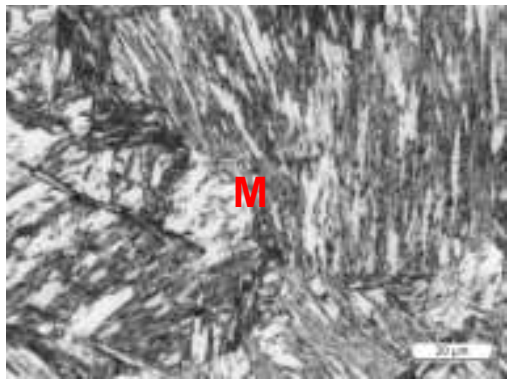

(d) $50^{\circ} \mathrm{C} / \mathrm{s}$

Figure 4 (a) CCT diagram corresponding to $\mathrm{CMnNbMoB}$ steel after Direct Quenching cycle.

Microstructures obtained after different cooling rates: (b) 0.1 , (c) 10 and (d) $50^{\circ} \mathrm{C} / \mathrm{s}$.

The ability of Mo delaying phase transformation and promoting the formation of more bainitic/martensitic microstructure is confirmed when the evolution of Vickers hardness as a function of cooling rate is analyzed [2]. In Figure 5, the Vickers hardness is plotted for entire cooling rate interval and different steel grades, after DQ+CQ schedule. In addition, the critical cooling rates (Crit CR) for reaching fully martensitic microstructure are also added in the graph. The influence of cooling rate and addition of $\mathrm{Nb}$ or Mo is clear. Higher hardness values are measured as the cooling rate increases and microalloying elements are added. As expected, the softer microstructures are obtained for $\mathrm{CMnB}$ steel and the higher hardness values are quantified for the steel containing Mo. When Mo is added, the ferritic region is significantly reduced and the bainitic field is extended to lower temperatures, due to the potential of Mo retarding phase transformation and ensuring hardenability. Additionally, the results suggest that the critical cooling rate to achieve fully martensitic microstructure is considerably reduced when the steel contains Mo. Microstructures composed of only martensite are achieved for cooling rates higher than $100^{\circ} \mathrm{C} / \mathrm{s}, 100^{\circ} \mathrm{C} / \mathrm{s}, 20^{\circ} \mathrm{C} / \mathrm{s}$ and $50^{\circ} \mathrm{C} / \mathrm{s}$, for the $\mathrm{CMnB}, \mathrm{CMnNbB}, \mathrm{CMnMoB}$ and $\mathrm{CMnNbMoB}$ steels, respectively. For the NbMo grade, a higher critical cooling rate for obtaining fully martensitic microstructure is measured compared to Mo steel. When $\mathrm{Nb}$ is added to a Mo microalloyed steel, higher accumulation of deformation is ensured on the austenite, leading to an increase in the ferrite nucleation sites. This could also promote a faster nucleation of the bainitic laths and an increase of the critical cooling rate for obtaining martensite [5]. As shown in the FEGSEM images in Figure 6 , the formation of martensitic microstructure is achieved in Mo containing steels for higher 
cooling rates than $20^{\circ} \mathrm{C} / \mathrm{s}$. Conversely, for the reference steel, no presence of martensite is noticed and fully bainitic phases are observed.

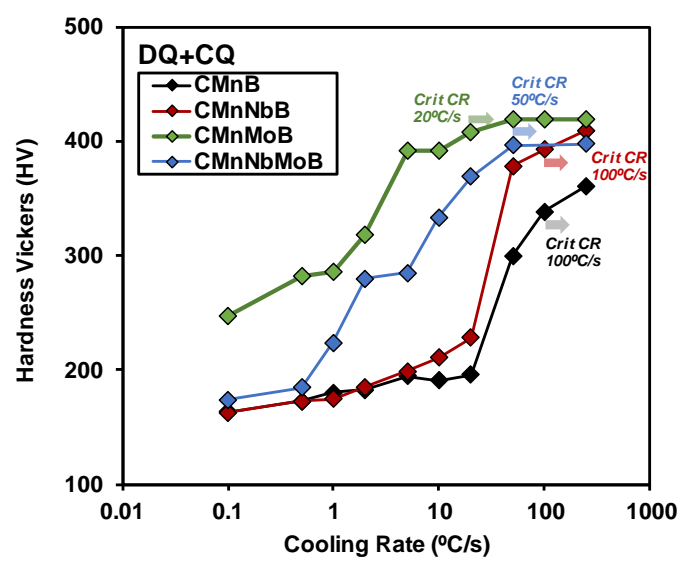

Figure 5 Evolution of hardness as a function of cooling rate (DQ+CQ strategy).

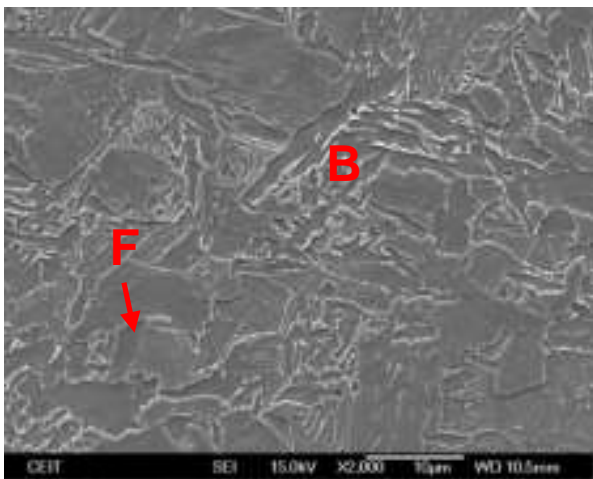

(a)

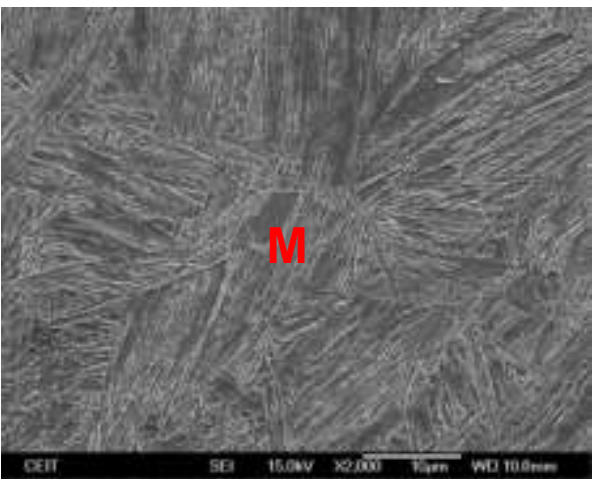

(b)

Figure 6 Influence of addition of molybdenum on the microstructure obtained after a cooling rate of $20^{\circ} \mathrm{C} / \mathrm{s}$ (Direct Quenching cycle): (a) CMnB and (b) $\mathrm{CMnMoB}$.

Hot rolling simulation: Effect of austenite conditioning on the final microstructure

Finally, multipass torsion tests were carried out, in order to simulate different hot rolling strategies and to analyze the influence of the amount of total reduction during finishing and its effect on the final martensite. Concerning the effect of accumulation of deformation on the austenite prior to transformation, different trends could be noticed depending on the steel grade. For the CMn and the lowest deformation level, besides martensite, bainitic phases are observed in the resulting microstructure. In addition, analyzing the effect of amount of strain, the presence of bainitic phases is more evident for the High Deformation condition. A softer microstructure is achieved for the High Deformation condition (HV decreases from 290.2 to $256.2 \mathrm{HV}$ ). The increment of accumulation of deformation on austenite promotes the formation of more bainitic phases and softer microstructures. In contrast, for all deformation levels, fully martensitic microstructures are observed in Mo- and Nb-Mo added steels and the effect of deformation level is less significant. 


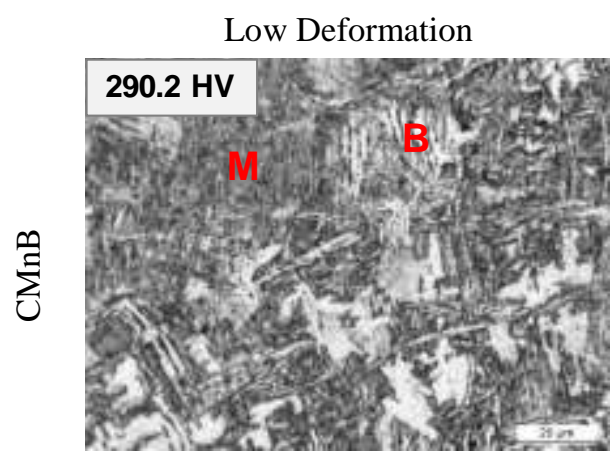

(a)

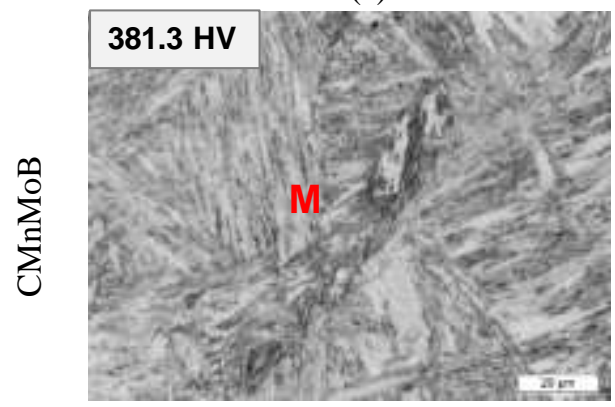

(c)

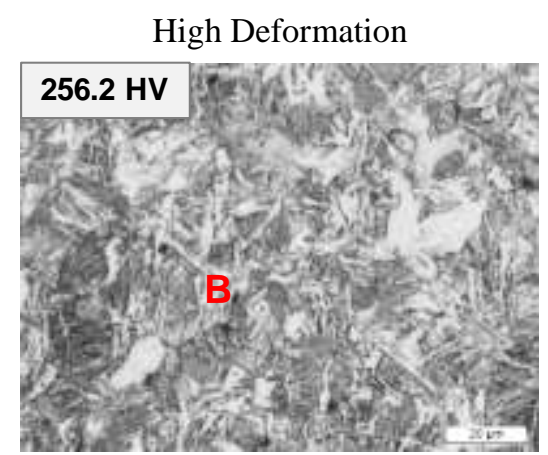

(b)

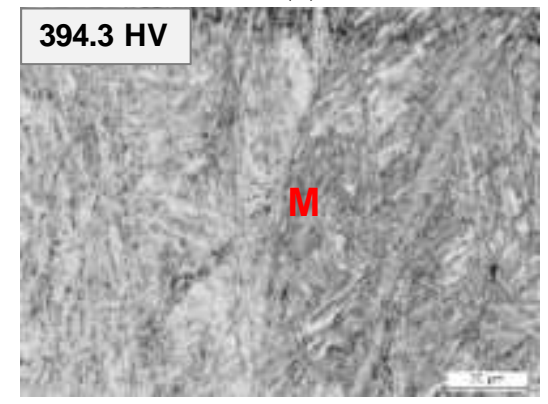

(d)

Figure 7 Effect of austenite conditioning on the transformed microstructure. Optical micrographs corresponding to $(\mathrm{a}, \mathrm{b}) \mathrm{CMnB}$ and $(\mathrm{c}, \mathrm{d}) \mathrm{CMnMoB}$ and different deformation levels on austenite: (a,c) Low Deformation and (b,d) High Deformation.

In some conditions, the austenite structure is not properly revealed by picric acid. The reconstruction by EBSD technique of the prior austenite measured from the inherited orientations in the martensitic microstructure has become a powerful tool [6]. In addition to chemical etching, this technique could be successfully applied to visualize the austenite structure. As an example, in Figure 8a, the austenitic structure (etched by picric acid) of the CMnNbMoB grade with Low Deformation is presented. Figure 8b shows the IPF (Inverse Pole Figure) map obtained for the martensitic microstructure in the same zone. Considering the reconstruction procedure described in Ref 6, the reconstructed prior austenite could be achieved, as shown in the IPF map shown in Figure 8c. When the austenitic structure observed by optical microscopy (Figure 8a) and predicted by reconstruction methodology (Figure 8c) are compared, a reasonable correlation is observed. In Figure $8 \mathrm{~d}$, austenite grain size measurements performed by optical microcopy (equivalent diameter method) and the reconstruction procedure using EBSD are compared. Similar austenite size distributions, as well as mean austenite sizes are observed in both cases. Mean austenite sizes of 60.3 and $59.7 \mu \mathrm{m}$ are quantified, by optical microscopy and reconstruction procedure, respectively.

\section{Conclusions}

Chemical composition and processing parameters define the suitability of a steel grade for ultrahigh resistance quenched and tempered application. The addition of Molybdenum affects significantly the formation of a fully martensitic structure after quenching. The different alternatives for the quenching practice, i.e. conventional or direct after thermomechanical conditioning of austenite, affect directly the transformed phase combination as well as the final hardness. The EBSD-based austenite reconstruction allows for a complete understanding of the austenite conditioning and the relationship between rolling process and final martensitic structure. 


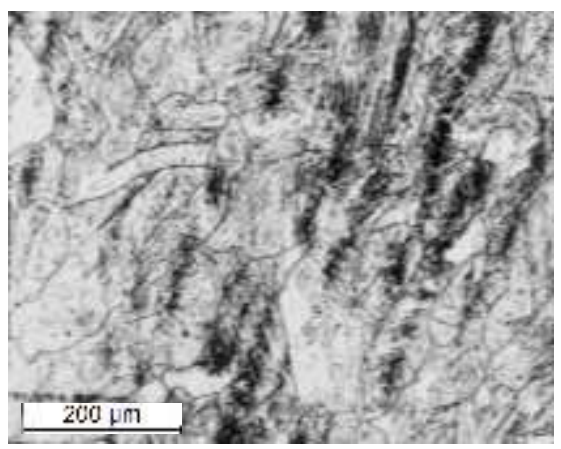

(a)

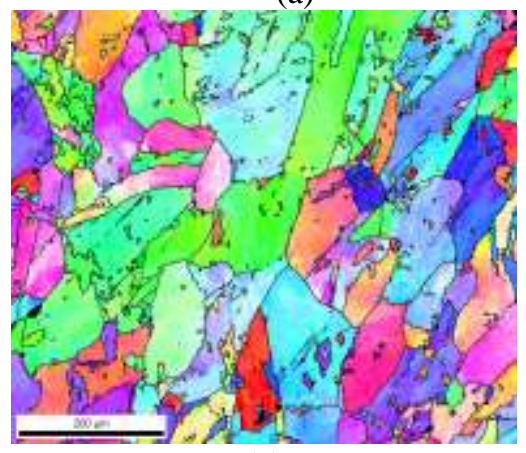

(c)

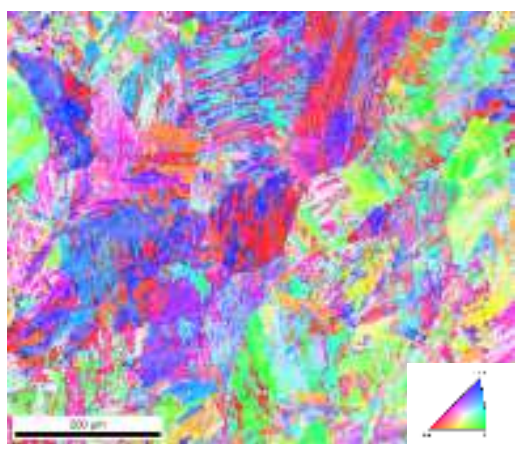

(b)

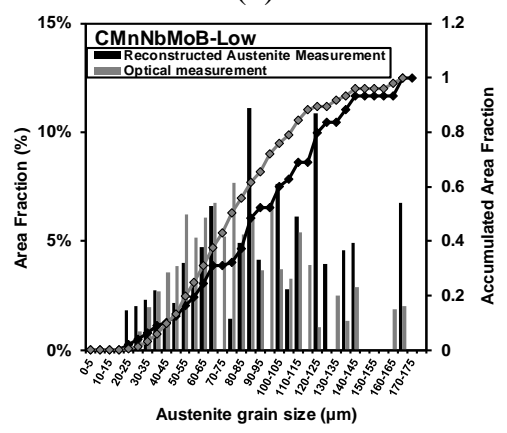

(d)

Figure 8 (a) Austenitic structure for $\mathrm{CMnNbMoB}$ steel and low deformation, (b) Inverse Pole Figure of the martensitic microstructure, (c) Reconstructed Austenite and (d) Austenite size distributions measured by optical microscopy and austenite reconstruction procedure.

\section{Acknowledgements}

The authors would like to acknowledge the International Molybdenum Association (IMOA) for funding this project.

\section{References}

[1] H. Mohrbacher, "Synergies of niobium and boron microalloying in molybdenum based bainitic and martensitic steel", Fundamentals and Applications of $\mathrm{Mo}$ and $\mathrm{Nb}$ alloying in High Performance Steels", Vol 1, CBMM, IMOA and TMS, (2014), 83-108.

[2] P. Cizek, B.P. Wynne, C.H.J. Davies, and P.D. Hodgson, "The Effect of Simulated Thermomechanical Processing on the Transformation Behavior and Microstructure of a LowCarbon Mo-Nb Linepipe Steel”, Metall. Mater. Trans. A 46, (2015), 407-425.

[3] T. Hara, H. Asahi, R. Uemori, and H. Tamehiro, "Role of combined addition of niobium and boron and of molybdenum and boron on hardenability in low carbon steels", ISIJ Int. 44 (2004), 1431-1440.

[4] D.Q. Bai, S. Yue, W.P. Sun and J.J. Jonas, "Effect of Deformation Parameters on the NoRecrystallization Temperature in Nb-Bearing Steels", Met. Trans., 24 (1993), 2151-2159.

[5] A.K. Lis and J. Lis, "Effect of Hot Deformation and Cooling Rate on Phase Transformations in Low Carbon HN5MVNb Bainitic Steel”, Mater. Sci. Forum, 539-543 (2007), 4620-4625.

[6] L. Sanz, B. Pereda and B. López, "Validation and Analysis of the Parameters for Reconstructing the Austenite Phase from Martensite Electron Backscatter Diffraction Data", Metall. Mater. Trans. A, 48 (2017), 5258-5272. 